\title{
NÃO É UMA REDE QUE FLUI - DA INVISIBILIDADE ÀS POSSIBILIDADES DE NOVOS MODOS DE CUIDAR: A VIOLÊNCIA CONTRA AS MULHERES NA SAÚDE MENTAL
}

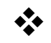 \\ Yanaê Maiara Meinhardt \\ Universidade de Santa Cruz do Sul - UNISC - Brasil \\ Gabriela Felten da Maia \\ Universidade de Santa Cruz do Sul - UNISC - Brasil
}

\section{Resumo}

Este trabalho, de cunho qualitativo, objetiva refletir sobre a inserção da violência contra as mulheres no campo da saúde, especificamente a saúde mental. Para compor a análise, utilizamos material da observação participante, no decorrer do estágio em Psicologia, realizado no primeiro semestre de 2015, em um serviço da rede pública de saúde do município de Santa Cruz do Sul, interior do Rio Grande do Sul, o Centro de Atenção Psicossocial II (CAPS II). A violência contra as mulheres é um fenômeno mundial, que se expressa em diversas formas, são elas: simbólica, física, moral, psicológica, patrimonial e sexual, sendo o feminicídio a expressão máxima de violência. No Brasil, são altos os índices de violência conjugal contra as mulheres, evidenciando esse tipo de violência como um problema grave de saúde pública. Observamos que as discussões de gênero, conforme a perspectiva feminista, se faz necessária nos serviços de saúde mental, dada a importância da transversalidade de gênero nas políticas públicas e a visibilidade do tema no campo da saúde. Ainda há invisibilidade e silenciamentos em relação ao tema, por isso, consideramos que a inserção dessa discussão possibilitará promovermos tanto a saúde quanto a cidadania que o cuidado em saúde mental pode proporcionar.

Palavras-chave: gênero; mulheres; saúde mental; violência.

\section{Introdução}

Este trabalho emerge a partir da observação participante do estágio integrado em Psicologia, em um serviço especializado em saúde mental, o Centro de Atenção Psicossocial II (CAPS II), no munícipio de Santa Cruz do Sul, município de médio porte, localizado no interior do Estado do Rio Grande do Sul.

Trata-se de um trabalho qualitativo que tem por objetivo pensar a violência contra as mulheres no campo da saúde e as possibilidades de promoção de saúde e cidadania que o 
cuidado em saúde mental pode proporcionar. Utilizamos para embasamento do quadro teórico discussões feministas de gênero, que perpassam os campos violência contra as mulheres e saúde. A partir destas discussões procuramos refletir sobre as intervenções realizadas até o momento no estágio.

O CAPS II do município foi inaugurado em 17 de março de 1997. Atende pessoas acima de 18 anos em sofrimento psíquico, via encaminhamento da rede básica de saúde entre outras redes de saúde e assistência. De acordo com a portaria GM no 336/2002, possui capacidade operacional para atender uma população entre 70.000 e 200.000 habitantes. Atualmente o serviço conta com mais de 10.000 prontuários, sendo a maioria destes, conforme a equipe do serviço, de mulheres. O serviço realiza atendimentos individuais, como psicoterapia e triagem, e atividades coletivas, como grupos e oficinas. O CAPS II de Santa Cruz do Sul atua com uma equipe multiprofissional, composta por uma terapeuta ocupacional, uma nutricionista, uma assistente social, uma enfermeira, duas técnicas em enfermagem, cinco psicólogas, um educador físico e quatro psiquiatras. Além destes, o serviço também conta com serviços de vigilância, cozinha, higienização, transporte, quatro estagiárias CIEE para as atividades administrativas e estagiárias da graduação dos cursos de Psicologia e Enfermagem. Grande parcela da equipe técnica atua no serviço desde a sua implementação no município, sendo desde a inauguração do serviço, uma equipe composta predominantemente por mulheres, com exceção da rotatividade de alguns homens na área técnica e administrativa.

Nas observações realizadas, o tema da violência contra as mulheres tornou-se evidente, na medida em que nos atendimentos, nos relatos das mulheres, apareciam situações de violência, por vezes expressa de maneira explícita, por vezes subliminarmente. Essa escuta possibilitou reflexões acerca da saúde mental das mulheres em situações de violência, como, também, da invisibilidade deste tema nas discussões da equipe.

Enquanto ativista do movimento feminista, a estagiária se reconhece implicada no enfrentamento à violência contra às mulheres e percebeu a necessidade de intervenções no local de estágio, por entender que as violências vivenciadas impactam a saúde mental das mulheres. Mobilizada por essa questão, a estagiária foi a procura de uma parceira ativista e também pesquisadora desta temática para refletir e contribuir nas intervenções planejadas. Juntas construíram as oficinas que compõem objeto de reflexão do presente artigo.

As oficinas foram pensadas considerando a importância da violência ser inserida no contexto do atendimento dos serviços de saúde, em razão do impacto na saúde física e psíquica dos indivíduos. O Mapa da Violência (WAISELFISZ, 2012) apontou altas taxas de violência contra as mulheres nos últimos anos, expressando a relevância social de discutir esta 
problemática e pensar em estratégias de enfrentamento à violência em conjunto com todas as esferas sociais, inclusive no campo da saúde, considerando o índice de homicídios em decorrência do gênero e os agravos psíquicos cujas mulheres sofrem em situação de violência.

É ao lançar um olhar para este tema e sua inserção no serviço de saúde mental, que passamos a discutir a emergência de um problema que por muito tempo esteve invisível na esfera privada, sendo alçado a um problema de saúde pública.

\section{Em briga de marido e mulher se mete a colher}

A violência contra as mulheres é um fenômeno mundial, que afeta mulheres e suas famílias. Esta problemática abarca diversas formas de violência, são elas: simbólica, expressa através da força da ordem masculina, naturalizada na cultura e sociedade, são as formas de dominação não questionadas, mas que se encontram subliminarmente nas atividades de caráter desigual atribuídas a cada sexo; física, qualquer ação ou omissão que atinja a integridade física; moral, qualquer ação destinada a caluniar, difamar ou injuriar a reputação ou honra da mulher; psicológica, qualquer ação ou omissão com o objetivo de controlar ações, comportamentos, crenças e decisões por meio da intimidação, manipulação, ameaça, humilhação, isolamento, entre outras condutas quaisquer que provoquem prejuízo à saúde psicológica; patrimonial, qualquer conduta que implique retenção, subtração, destruição parcial ou total de objetos, instrumentos de trabalho, documentos pessoais, bens, valores e direitos ou recursos econômicos; e sexual, qualquer ação que force contato sexual com uso da força, intimidação, coerção, chantagem, suborno, manipulação e ameaça, como a tortura, tráfico de mulheres, prostituição forçada, sequestro, assédio sexual, abuso sexual, violência institucional cometida pelo Estado e seus agentes (BRASIL, 2007; CORRÊA, 2011). É um problema social de grande proporção, sendo o feminicídio ${ }^{1}$ a expressão máxima da violência.

No Brasil, o feminicídio vitimiza $4,4 \%$ da população, ocupando a $7^{\circ}$ posição no ranking internacional de homicídios femininos por país. O perfil das vítimas são mulheres com idade entre 20 e 29 anos, sendo em 71,8\% dos casos a residência como o local de maior incidência das violências e o principal meio utilizado, em 49,2\% dos casos, é a arma de fogo. No Rio Grande do Sul, o feminicídio afeta $4,1 \%$ da população, ocupando a $19^{\circ}$ posição no ranking

\footnotetext{
1 Feminicídio é o assassinato de mulheres motivado pelo machismo, expresso nas relações de gênero. Por exemplo, um ex-companheiro que não aceita o término da relação pois considera a mulher sua posse; o marido que agride a esposa porque ela foi à uma festa sem permissão, etc.
} 
nacional de homicídios femininos por UFs (WAISELFISZ, 2012). Estes dados comprovam que a violência contra as mulheres e a violência de gênero é um problema grave de saúde pública.

Recentemente foi aprovada a Lei 13.104, de março de 2015, conhecida como a Lei do Feminicídio, que prevê o feminicídio como circunstância qualificadora do crime de homicídio e o inclui no rol dos crimes hediondos. A aprovação desta lei proporcionou discussões e novos significados do papel das mulheres na sociedade.

Legitimado pelo Código Penal de 1940 (Código vigente) no artigo 23, inciso II, até a década de 90, mulheres eram assassinadas em justificativa da legítima defesa da honra (MARABEZZI, 2010), naturalizando a completa submissão da mulher à uma suposta virilidade masculina superior, desta forma, favorecendo a vulnerabilidade à todas as formas de violência e exploração. Para desconstruir tais noções cristalizadas em nossa sociedade e garantir acesso aos direitos humanos das mulheres, foram importantes neste processo o movimento feminista e o movimento de mulheres.

É neste contexto que, a partir da década de 70, emerge reivindicações do movimento feminista e movimento de mulheres para pautar a violência contra as mulheres na agenda pública do país (BRASIL, 2013). Através do movimento feminista "Quem ama não mata!" no final da década de 70, foi possível desencadear uma campanha nacional para denunciar que homens assassinavam suas companheiras e ainda ficavam impunes utilizando da alegação de legítima defesa da honra (MARABEZZI, 2010).

Houve avanços nas últimas três décadas no que tange a atenção à esta problemática, desde a I Conferência Mundial da Mulher em 1975, passando pela aprovação da Assembleia Geral das Nações Unidas da Convenção pela Eliminação de Todas as Formas de Discriminação Contra a Mulher (CEDAW), em 1979 (MENEGHEL, 2009). Em 1980 o Movimento das Mulheres iniciou parcerias com o Estado para implementar políticas no combate à violência, os temas violência contra a mulher e saúde passaram a ser articulados ao decorrer desta década, em que emergem as políticas públicas e outras iniciativas abordando estes temas. Em 1990 a violência de gênero passa a ser reconhecida pela Organização Mundial da Saúde (OMS) como um problema de saúde pública, no mesmo ano o feminicídio perde a justificativa de legítima defesa da honra e passa para a categoria de crime hediondo, em 1993 a Organização Pan Americana de Saúde (OPAS) também reconheceu a problemática como um problema de saúde pública (BRASIL, 2013; MARABEZZI, 2010; MENEGHEL, 2009).

As experiências adotadas pelo setor público que ficaram mais conhecidas foram as Delegacias de Defesa da Mulher (1985) e os Centros de Referência em Saúde da Mulher. A institucionalização das demandas em relação as mulheres ocorreu, primeiramente, com o 
Conselho Nacional dos Direitos da Mulher (CNDM) e com a Secretaria de Estado dos Diretos da Mulher. De 1985 até 2002, o Programa Nacional de Combate à Violência Contra a Mulher teve seu foco na construção de Casas de Abrigo e na criação de Delegacias Especializadas no Atendimento à Mulher (DEAM). Em 2003, com a Secretaria Especial de Políticas para as Mulheres (SPM) houve espaço para iniciar a formulação da Política Nacional de Enfrentamento à Violência Contra a Mulher, sendo sua importância reafirmada na I Conferência Nacional de Políticas para as Mulheres em 2004, junto ao Plano Nacional de Políticas para as Mulheres que estabeleceu o enfrentamento a todas as formas de violência (BRASIL, 2007).

Um aspecto fundamental nas ações do governo é o princípio da transversalidade de gênero a ser adotado em todas as políticas públicas do Estado, que consiste na elaboração de uma matriz que possa orientar competências políticas, institucionais e administrativas, além de responsabilizar os agentes públicos na superação das assimetrias de gênero nas diferentes esferas do governo. Trata-se de uma ação integrada e sustentável entre as diversas instâncias governamentais, repercutindo na eficácia das políticas públicas. Na Conferência de Beijing (1995), foi proposto o conceito de transversalidade de gênero como uma estratégia básica de promoção de equidade, que o Brasil, assim como os demais Estados membros, se comprometeu a seguir (MENEGHEL, 2009). O Pacto Nacional de Enfrentamento à Violência Contra as Mulheres (2007), também coloca a transversalidade de gênero como uma das três premissas de suas ações, junto à intersetorialidade, que propõe uma nova forma de trabalhar, governar e construir políticas públicas voltadas para a promoção da saúde e melhoria da qualidade de vida, visando alcançar resultados integrados de efeitos sinérgicos (BERNARDI et al, 2010) e a capilaridade, que consiste em como estender ações para incluir todos os atores sociais envolvidos. O Pacto Nacional de Enfrentamento à Violência Contra as Mulheres junto a Política Nacional de Enfrentamento à Violência Contra as Mulheres também apontam a necessidade da articulação entre o Sistema Único de Saúde, Sistema Único de Assistência Social; do Sistema Único de Segurança Pública, Poder Judiciário e Ministério Público (BRASIL, 2011), desconstruindo a noção de que a violência de gênero não é um problema de saúde.

\section{A invisibilidade da violência contra as mulheres na saúde mental}

É curioso a quantidade de mulheres deprimidas, com suas tristezas “inexplicáveis”, nos serviços de saúde, desesperadamente nos dizem "eu não sei porque tô assim". Ao fazer a pergunta "como é a tua rotina?" emergem em suas falas a complexa dimensão de violência, que nem sempre estão expressas no corpo: passam o dia em casa, limpando-a e cozinhando, 
quando a casa não está "bem limpa" conforme critério do companheiro ou a comida não está boa, ocorre uma série de abusos verbais, inferiorizando a mulher; não podem trabalhar fora de casa, pois o companheiro liga constantemente com perguntas persecutórias e muitas vezes seguida de ameaças; qualquer conflito familiar é de responsabilidade dela; tem suas roupas íntimas inspecionadas pelo companheiro; seus trajetos vigiados; seu corpo à disposição dele, quando e como ele quiser; também são ameaçadas de morte sobre a possível separação futura.

Embora a violência esteja presente no cotidiano do serviço de saúde mental, um trabalho específico, com foco nas situações de violência e empoderamento das mulheres, trabalhando as dimensões de gênero e violência, não foi observado. Foi a partir do ativismo da estagiária que sua escuta sensibilizou-se para as falas das mulheres que sofrem violência conjugal e, a partir deste último aspecto, identificou a relevância deste tema ser discutido no campo da saúde e a necessidade de intervenções no local de estágio.

A estrutura das intervenções priorizou etapas: nos meses de março à maio a construção do projeto de trabalho, nos meses de junho e julho a realização de oficinas com a equipe do serviço, com o cronograma dos encontros semanais com a duração de aproximadamente uma hora pré-estabelecidos, em que se abordaria temas específicos em cada encontro, totalizando 8 encontros, para, a partir do mês de agosto, dar início ao grupo de fortalecimento com as mulheres. Paralelamente a este projeto de trabalho, a estagiária produziu uma análise institucional no decorrer de 4 meses de observação participante no local de estágio, cujo o tema violência contra as mulheres no campo da saúde, especificamente na saúde mental, é o objeto de análise.

Até o momento foram realizadas as oficinas com a equipe enquanto intervenção no serviço, conduzidas pela parceira ativista da estagiária. A mobilização para as oficinas emerge a partir da invisibilidade dos sintomas de violência expressos nos agravos psíquicos e seus impactos na saúde mental das usuárias. Alguns autores têm destacado que os profissionais de saúde têm dificuldade em identificar a maioria dos casos de violência ou nem chegam a registrar em prontuários, não incluindo a questão como parte do atendimento.

Pesquisas tem demonstrado que as equipes de saúde não se sentem capazes de prestar atenção integral às mulheres em situação de violência, referem falta de formação profissional, argumentam que há falta de suporte institucional e equipe multidisciplinar para o atendimento, limitam-se a tratar as lesões físicas e a referenciá-las ao setor policial. Além disso, apesar da existência de um Sistema de Notificação para as Violências, instituído como atividade compulsório do setor de saúde, não existem protocolos específicos que avaliem o risco iminente e não há disponibilidade de atividades de cunho individual ou coletivo que possam promover o 
fortalecimento destas mulheres (SCHRAIBER, D'OLIVEIRA, 1999; SCHRAIBER et. al., 2002)

Segundo Minayo (2004), a violência é uma questão social e não é objeto próprio da saúde. Porém, ela se torna um tema desse campo em decorrência do impacto que provoca na qualidade de vida, pelas lesões físicas, psíquicas e morais que acarreta e pelas exigências de atenção e cuidados dos serviços médico-hospitalares. A concepção ampliada de saúde torna a violência objeto da intersetorialidade, na qual o campo médico-social se integra.

Como destacam Jorge e Oiveira (2007), os impactos da violência na saúde mental das usuárias podem variar entre problemas físicos, como lesões, síndromes de dores crônicas e distúrbios gastrointestinais. Há problemas mentais, como ansiedade, depressão, entre outros agravos psíquicos, além de aumentar a incidência do tabagismo, bebidas alcoólicas e outras drogas, quais não são compreendidos pelos serviços de saúde como consequências da violência sofrida, mas interpretados pelos serviços como usuárias "poliqueixosas" sem uma causa patológica evidente ou específica.

Schraiber (2001, p. 105-106) argumenta que

\begin{abstract}
Os profissionais da saúde lidam mal com demandas que nem sempre se caracterizam como adoecimentos, ainda que constituam, de fato, sofrimentos com potenciais danos à saúde. Nos serviços de atenção primária, em prontoatendimentos ou mesmo em prontos-socorros, muitas dessas situações representam verdadeiros obstáculos comunicacionais, já que são expressas na forma de múltiplas queixas, dores de imprecisa localização no corpo ou sem correspondência a patologias conhecidas. Sendo muitas vezes situações diagnósticas imprecisas, as demandas trazidas pelas mulheres que estão vivendo situações de violência com frequência são assumidas como situações assistenciais fadadas ao insucesso.
\end{abstract}

É muito comum as próprias mulheres em situação de violência não reconhecerem e compreenderem a situação em que se encontram como violência, em razão de ainda permanecer no imaginário social que violência significa apenas agressão física, ou não percebem os sintomas que apresentam como decorrendo das situações de violência. Não apenas estas mulheres podem não reconhecer a violência, mas também o serviço que as atendem e que, em decorrência da invisibilidade do tema, naturalizam o sofrimento da mulher nas relações conjugais, familiares, entre outras. Segundo Meneghel (2009), os profissionais têm dificuldade para lidarem com um problema que necessita de uma abordagem diferente da que foram socializados a empreender.

Nas reuniões de equipe do serviço, discutimos pautas, informes de toda ordem (eventos, atividades e mudanças no serviço, quer seja na estrutura, organização ou equipe) e por último, discutimos os casos. Neste momento discutimos aqueles casos, predominantemente de 
mulheres, mais críticos; como usuárias no plano intensivo em decorrência dos riscos para si ou para outros, agravos psíquicos de toda ordem, conflitos conjugais/familiares graves; usuárias recentes no serviço cujo caso necessita de maior atenção ou usuárias cronificadas no serviço.

Nas falas das técnicas aparecem situações de violência sofridas pelas usuárias do serviço, porém ao discutir os casos, os relatos de violência pouco são interpretados como tal, quando o são, a violência emerge em segundo plano de suas falas. Também os casos que incluem violência contra as mulheres, comumente não são discutidos em reunião de equipe sobre os possíveis desdobramentos em cada caso, como abordar a violência, quais as orientações e encaminhamentos adequados e as possíveis estratégias de enfrentamento à violência. Houve momentos em que alguns casos dispararam reflexões na equipe para pensar a (des)articulação com a rede pública, em que a equipe mostrou-se sem saber como proceder, como realizar os encaminhamentos e os procedimentos adequados, o que indica a ausência de um protocolo instituído e constituído para o atendimento em casos de violência contra as mulheres.

A violência sofrida pelas usuárias do serviço por vezes são registrados nos prontuários, se restringindo à relação entre técnica e usuária, Conforme algumas técnicas referiram, trabalham as questões da violência no atendimento individual com a usuária, se limitando ao espaço do atendimento, muitas vezes sem qualquer articulação com a equipe para pensar como as questões de violência podem ser trabalhadas como um tema da saúde mental enquanto demanda do serviço. A abordagem da violência restrita ao espaço do atendimento culmina na invisibilidade do tema no serviço, que está acompanhada da noção de que a principal personagem para que a violência seja abordada é a própria mulher, deixando de colocarem a violência contra as mulheres como parte de suas demandas no serviço, isto pode ser chamado de "recusa tecnológica", compreendida como o reforço da invisibilidade da violência, pautada nas representações e concepções dos profissionais sobre as tecnologias e recomendações no campo da Saúde (MENEGHEL, 2009).

Enfrentar a violência vivida pelas usuárias do serviço é algo que também depende da relação entre profissionais e usuárias (SCHRAIBER, 2001), as mulheres que tentam romper com a violência, muitas vezes tem seu percurso dificultado e obstruído pela qualidade das relações estabelecidas entre as mulheres e os apoios que buscam, com base nas interações com as instituições que as encontram (SAGOT, 2000). Meneghel (2009) afirma que um dos primeiros movimentos para romper com a violência é romper com os silêncios que dependem da qualidade destes encontros, se são interativos ou não. 
Muitas mulheres evitam falar sobre a violência que sofrem por medo, vergonha ou culpa pelo ocorrido, os familiares e seus próximos não acreditam que devam se solidarizar, pensam que isto seria intromissão em assuntos privados. Já os profissionais evitam falar sobre porque não sabem o que fazer, como proceder, ou não querem se adiantar à mulher (MENEGHEL, 2009). Todos estes entendimentos refletem que a violência contra as mulheres ainda é colocada no plano individual e privado de quem a sofre.

Uma pesquisa realizada por Kiss (2004) em 19 serviços de saúde da rede pública em São Paulo, revela que, mesmo quando os profissionais valorizam o relato da mulher em situação de violência, desacreditam na competência do enfrentamento à violência com seus conhecimentos e habilidades em saúde, comparando-se à ação policial. A ação policial é/pode ser uma das ferramentas para enfrentar a violência contra as mulheres, vale lembrar que a ação policial, quando não em flagrante, só ocorre se a mulher desejar, para tal é minimamente necessário romper com o silêncio e trabalhar o fortalecimento da mulher para que se sinta segura em procurar instituições jurídicas e de segurança pública.

Portanto, o papel da Saúde é atuar dentro de sua perspectiva científica e assistencial, produzindo contribuições nas três esferas de atuação características: assistência terapêutica aos casos, prevenção e promoção. Situar a violência no interior da Saúde Pública é convergente com a consolidação deste campo, que desde os anos 1970 esteve alinhado, ética e politicamente com os movimentos de luta por equidade social, entre eles o movimento feminista (MENEGHEL, 2009).

Quando o serviço atende usuárias em situação de violência, tal demanda precisa ser trabalhada em conjunto com outros serviços. Geralmente, em nosso município, mulheres em situação de violência têm especificamente essa problemática atendida por outros serviços, como o Centro de Referência Especializado de Assistência Social (CREAS), Delegacia Especializada em Atendimento à Mulher (DEAM) e o Escritório dos Direitos da Mulher em parceria com o Conselho Municipal dos Direitos da Mulher (CMDM). Identificar junto à mulher quais são as suas prioridades nesta situação, se tais prioridades já estão sendo atendidas por outros serviços e caso estejam, quais são estes serviços, contatá-los e articular junto à mulher e a estes outros serviços o enfrentamento à violência se faz necessária. Do contrário, deve ser realizado orientações e possíveis encaminhamentos.

Chamamos a atenção para a transversalidade, fundamental em qualquer política pública, presente também no Pacto Nacional de Enfrentamento à Violência Contra a Mulher, é considerada uma estratégia básica de equidade social, o que inclui equidade de gênero, consiste na elaboração e prática de uma matriz política que permita orientar uma nova visão de 
competências políticas, institucionais e administrativas, proporcionando respostas às demandas de maneira eficaz nas políticas, ações e programas governamentais (ALMEIDA, 2013).

Conforme aponta o Pacto Nacional de Enfrentamento à Violência Contra as Mulheres (2011), "a transversalidade de gênero visa garantir que a questão de violência contra a mulher e de gênero perpasse as mais diversas políticas públicas setoriais" como, também, a própria Política Nacional de Atenção Integral à Saúde da Mulher (2004) incorpora em sua última formulação a transversalidade de gênero e a violência de gênero como um problema de saúde:

Este documento incorpora, num enfoque de gênero, a integralidade e a promoção da saúde como princípios norteadores e busca consolidar os avanços no campo dos direitos sexuais e reprodutivos, com ênfase na melhoria da atenção obstétrica, no planejamento familiar, na atenção ao abortamento inseguro e no combate à violência doméstica e sexual (BRASIL, p. 5, 2004).

A Política Nacional de Atenção Integral à Saúde da Mulher amplia-se para além de aspectos biológicos e anatômicos, inserindo as dimensões de direitos humanos, cidadania, direitos sexuais e questões de gênero em sua última formulação, em 2004. Conforme essa política, as desigualdades históricas de poder entre homens e mulheres implicam num forte impacto nas condições de saúde das mulheres, afirmando que "as questões de gênero devem ser consideradas como um dos determinantes da saúde na formulação das políticas públicas”.

Para pensar em transversalidade e violência de gênero, precisamos, também, discutir gênero. Foi a partir da década de 70, do século XX, que o termo gênero começou a ser utilizado por um grupo de estudiosas anglo-saxãs, para argumentar que diferenças e desigualdades entre mulheres e homens eram social e culturalmente construídas e não biologicamente determinadas. Nas últimas quatro décadas, os estudos feministas adotaram perspectivas teóricas plurais, aliando-se com diferentes campos de estudo, em que ao decorrer do processo de institucionalização científica e acadêmica destas teorizações feministas houve confrontos e resistências com aqueles que reforçavam justificativas biológicas e teológicas para as desigualdades e diferenças entre mulheres e homens. Frente a este confronto as feministas se implicaram no desafio de demonstrar que não são as diferenças anatômicas e fisiológicas ou desigualdades socioeconômicas, compreendidas isoladamente, que definem as diferenças apresentadas como justificativa para as desigualdades entre mulheres e homens, mas aquilo que se torna possível pensar e dizer sobre mulheres e homens que vai constituir o que é inscrito no corpo, definido e vivido como masculinidade e feminilidade (MEYER, 2004). 
Para Scott (1994) é igualmente utilizado o gênero para designar as relações sociais entre os sexos e sua reflexão direciona-se no sentido da produção do saber sobre a diferença sexual. A partir da perspectiva pós-estruturalista, operar com o conceito de gênero, supõe:

\begin{abstract}
a) assumir que diferenças e desigualdades entre mulheres e homens são social, cultural e discursivamente construídas e não biologicamente determinadas; b) deslocar o foco de atenção da 'mulher dominada, em si' para a relação de poder em que tais diferenças e desigualdades são produzidas, vividas e legitimadas; c) explorar o caráter relacional do conceito e considerar que as análises e intervenções empreendidas neste campo de estudos devem considerar ou, pelo menos, tomar como referência, as relações - de poder - e as muitas formas sociais e culturais que, de forma interdependente e interrelacionada, educam homens e mulheres como "sujeitos de gênero"; d) 'rachar' a homogeneidade, a essencialização e a universalidade contidas nos termos mulher, homem, dominação masculina e subordinação feminina, dentre outros e, com isso, tornar visíveis os mecanismos e estratégias de poder que instituem e legitimam estas noções; e) explorar a pluralidade, a conflitualidade e a provisoriedade dos processos que delimitam possibilidades de se definir e viver o gênero em cada sociedade, nos seus diferentes segmentos culturais e sociais (MEYER, p. 3, 2004).
\end{abstract}

Meyer (2004), alinhada com essas discussões pós-estruturalistas do feminismo, ao discutir teorias e políticas de gênero e a institucionalização deste campo nas políticas públicas, aponta que a incorporação da transversalidade de gênero na Política Nacional de Atenção Integral à Saúde da Mulher:

(...) explicita como uma de suas diretrizes que "a elaboração, a execução e a avaliação das políticas de saúde da mulher deverão nortear-se pela perspectiva de gênero (...)", uma vez que mulheres e homens, “(...) em função da organização social das relações de gênero, também estão expostos a padrões distintos de sofrimento, adoecimento e morte (MEYER, p. 1, 2004).

Assim, os estudos que articulam os campos gênero e saúde e seus impactos nas políticas públicas, possibilitam entrelaçar conhecimentos e modos de cuidado, que tecem em conjunto saberes e práticas que promovem saúde, direitos e cidadania, bem como estão de acordo com as diretrizes do Sistema Único de Saúde, especialmente as doutrinas de equidade e integralidade.

\title{
Tecendo novas possibilidades: o desenrolar das oficinas
}

Considerando as discussões sobre a Saúde da Mulher presente na política pública em saúde e o combate às desigualdades de gênero como também uma questão de saúde pública é que surge a proposta das oficinas a ser realizada com a equipe técnica do CAPS II, como proposta de intervenção capacitadora. O objetivo era sensibilizar a escuta das técnicas para esta problemática e seus atravessamentos na rede pública, a fim de pensar tanto a saúde mental das 
mulheres em situação de violência, quanto evidenciar a violência de gênero como um tema também da área da saúde.

Ao decorrer do estágio, as observações realizadas proporcionaram reflexões acerca de como o serviço trabalha as questões de violência com suas usuárias. As oficinas foram pensadas a partir de temas invisibilizados no serviço, inserindo as respectivas discussões nas oficinas com a equipe, de acordo com o cronograma, com datas e temas específicos préestabelecidos.

As oficinas ocorriam no horário das reuniões de equipe, proposta realizada pela equipe para que o maior número de técnicas pudessem participar. Participavam em média 11 técnicas, variando conforme o dia realizado porque em alguns encontros evidenciou-se a dificuldade para se fazer presente, ou mesmo estarem pontualmente, todas as técnicas do serviço, ao mesmo tempo em que algumas técnicas faziam o esforço de anunciar o início da oficina e convocar toda a equipe para se fazer presente pontualmente neste momento.

As participantes foram todas mulheres, de idades aproximadamente entre 20 a 50 anos. A presença exclusiva de mulheres deve-se ao fato de que o próprio CAPS II é composto majoritariamente por profissionais mulheres. Participaram das oficinas as estagiárias da universidade, as estagiárias administrativas, as Psicólogas, a Assistente Social, a Enfermeira, as Técnicas de Enfermagem e a Terapeuta Ocupacional. Algumas das participantes identificamse com a discussão feminista e possuem uma postura crítica sobre as relações de gênero. Outras foram tomar conhecimento sobre essa discussão a partir das oficinas.

As oficinas foram organizadas em temas, considerando em um primeiro momento introdutório, em que se falaria dos conceitos de gênero e patriarcado, seguindo para a reflexão sobre a interface violência, gênero e saúde, para, então, realizar uma discussão de um Caso. Durante esses encontros debateu-se sobre a socialização de gênero e as formas de violência simbólica presente nessa socialização, também no desenrolar das oficinas foi-se pensando as expressões da violência contra as mulheres e a Política Nacional de Enfrentamento à Violência Contra a Mulher e o Pacto Nacional de Enfrentamento à Violência Contra a Mulher, as formas de encaminhamentos e a procedência adequada para os casos de violência contra as mulheres.

A discussão inicial provocou algumas mobilizações, como foi possível ser observado a partir da fala de uma técnica, ao relatar que após a oficina retornou para a casa com o companheiro e ambos conversaram por algumas horas sobre estereótipos de gênero e infância. A partir da fala dela observamos que a discussão inicial mobilizou uma reflexão pessoal, 
enquanto sujeitos engendrados pelas tecnologias de gênero ${ }^{2}$. Nessa conversa, a técnica trazia problematizações sobre a socialização das crianças e o modo como se educa os filhos a partir de normas de gênero.

Mas também houve momentos de resistências.

Inicialmente, as oficinas eram referenciadas pela equipe apenas como uma "proposta da estagiária", evidenciando que até esse momento havia um distanciamento da equipe, que não reconhecia seu papel em relação à discussão da violência de gênero como um problema da saúde mental e demanda do serviço. Esta referência foi diluindo-se no decorrer dos encontros, disparando mobilizações positivas em algumas técnicas da equipe, paralelo à resistência com os temas abordados, própria do processo de visibilizar aquilo que estava invisível.

Em alguns encontros o tema em questão por vezes dispersava o grupo em razão de alguns deboches sobre situações que envolviam o tema discutido, reproduzindo estereótipos de gênero, despotencializando a capacidade dos encontros em produzir saberes em conjunto sobre o campo, indicando o quanto ainda estamos imersos em lógicas patriarcais.

Além desse aspecto, observou-se que em muitos encontros o silêncio predominava, principalmente quando a equipe era questionada sobre a inserção da violência de gênero como um problema da saúde mental. No $6^{\circ}$ encontro em que foi discutida a rede de atendimento, a oficineira ao questionar a equipe se o serviço trabalha articulado com as questões de violência, houve silêncio por parte da maioria das técnicas, indicando o silenciamento da discussão no serviço.

Mas foi a partir da discussão de um Caso que se pode observar a equipe intensamente presente, implicada em pensar os desdobramentos possíveis para o caso abordado. Neste encontro, observou-se uma dinâmica interessante entre sugestões e dúvidas, de cunho colaborativo. A partir dessa experiência de discussão com o caso que emergem reflexões em grupo sobre as discussões realizadas.

A equipe relatou o quanto estas discussões abordaram um campo que para as técnicas é novo, produzindo, acerca da violência contra as mulheres, novos olhares, reflexões e a capacidade de reconhecer expressões de machismo perpetuadas por outrem e também aquelas que reproduzem, evidenciando a interferência das oficinas na vida particular e profissional.

\footnotetext{
2 Teresa de Lauretis (1994), entende gênero como as técnicas que produzem as formas de ser homem e ser mulher, aprendidas desde cedo.
} 
Suzana ${ }^{3}$ afirmou que "minha escuta ficou mais aguçada, mais atenta" complementada pelo exemplo utilizado pela Carolina, se referindo à sensibilidade da escuta "ó, isso é machismo".

Também trouxeram a mobilização para repensar práticas, inclusive no atendimento e o potencial multiplicador das oficinas, expresso na fala da Ana:

\begin{abstract}
No grupo de acompanhamento eu usei com eles um texto de uma socióloga que fala do "homem vagabundo" e "mulher vagabunda", ela discute a diferença dos significados atribuídos aos termos vagabunda e vagabundo em decorrência do gênero (Diário de Campo, agosto de 2015) .
\end{abstract}

Após Luana, outra estagiária de Psicologia, falar da importância do acolhimento das mulheres em situação de violência, foram disparadas reflexões acerca da rede pública, em que a equipe referenciou a fragilidade da rede, expressa na desarticulação entre os serviços, pois, conforme a equipe, é a falta de qualificação dos serviços que levam ao desconhecimento das possibilidades de articulação em rede, dificultando os encaminhamentos adequados. Helena destaca que "não é uma rede que flui, tem muitas possibilidades com as secretarias, mas a gente não fica sabendo", indicando a necessidade de capacitação dos serviços. A equipe, ao refletir sobre as fragilidades da rede, também pensou em possibilidades de fortalecimento, em como dialogar com a rede para uma melhor articulação e conhecer aquilo que tem disponível nos serviços para poder encaminhar e também dizer o que é o CAPS. Ana ao dizer que "independente de onde a mulher busque ajuda, quem atende deve acolher" e que, para isso deve estar capacitado, sintetiza em sua fala o que é o trabalho em rede articulado, tecido em conjunto.

Tais reflexões da equipe falam da riqueza de suas potencialidades, em que o processo de capacitação implicou o reconhecimento do papel da equipe na intervenção, a partir do reconhecimento que desconhecem a rede do município e que, em decorrência da fragilidade da mesma, não sabem como encaminhar.

\title{
Considerações finais
}

Dada a invisibilidade da violência contra as mulheres no campo da saúde, tornou-se fundamental a transversalidade de gênero nas políticas públicas de saúde do Estado e a incorporação efetiva destas nos serviços de saúde. Observamos a fragilidade da rede, expressa

Foi utilizado nomes fictícios para preservar a identidade das profissionais.

As falas das técnicas serão marcadas em itálico para diferenciar das citações bibliográficas. 
na dificuldade de articulação que o serviço encontra por não saber como encaminhar e quais são as possibilidades disponíveis.

Para o fortalecimento da rede de enfrentamento e atendimento às mulheres em situação de violência no munícipio, se torna necessário estudos sobre a violência de gênero e a interface com a saúde. Estudos como esses contribuem para a avaliação e monitoramento das políticas públicas, que podem contribuir para a qualificação dos serviços e articulação em rede, com vista a garantia dos direitos e promoção da saúde e cidadania das mulheres à uma vida sem violência.

A discussão da violência de gênero na saúde mental se faz necessária para o enfrentamento da violência contra as mulheres enquanto demanda da rede, considerando que, este é um problema grave de saúde pública. As oficinas com a equipe do CAPS II atuaram como uma das formas de inserção do tema no serviço, provocando novos olhares sobre as práticas, conceitos e o trabalho em rede, disparando reflexões na equipe sobre suas potencialidades.

\section{Referências:}

ALMEIDA, T. M. C.; BANDEIRA, L. M. A transversalidade de gênero nas políticas públicas. Revista do Ceam. 2013, v. 2, n. 1, p. 35-46. Disponível em: <http://periodicos.unb.br/index.php/revistadoceam/article/view/9735>. Acesso em: 17 mai. 2015 .

BERNARDI, Adriana Pigatto et al. Intersetorialidade - um desafio de gestão em Saúde Pública. Saúde \& Transformação Social. Florianópolis, v.1, n.1, p.137-142, 2010. Disponível em: <http://www.redalyc.org/pdf/2653/265319560020.pdf>. Acesso em: 17 mai. 2015.

BRASIL, Ministério da Saúde. Saúde, migração, tráfico e violência contra mulheres : o que o SUS precisa saber : livro-texto. Universidade de Brasília. Brasília: Ministério da Saúde, 2013. Disponível em:

<http://bvsms.saude.gov.br/bvs/publicacoes/saude_migracao_trafico_violencia_saber.pdf $>$. Acesso em: 24 mai. 2015.

Secretaria de Atenção à Saúde. Departamento de Ações Programáticas Estratégicas. Política nacional de atenção integral à saúde da mulher: princípios e diretrizes. Brasília: Ministério da Saúde, 2004. Disponível em:

$<$ http://bvsms.saude.gov.br/bvs/publicacoes/politica_nac_atencao_mulher.pdf $>$. Acesso em 02 ago. 2015.

BRASIL, Secretaria Especial de Políticas para as Mulheres. Enfrentamento à violência contra a mulher - Balanço 2006-2007. Brasília: 2007. Disponível em: < http://www.spm.gov.br/assuntos/ouvidoria-da-mulher/pacto-nacional/publicacao-pacto2007.pdf>. Acesso em: 24 mai. 2015.

BRASIL, Secretaria de Políticas para as Mulheres. Pacto Nacional de Enfrentamento à Violência contra as Mulheres. Brasília: 2011. Disponível em: < 
http://www.spm.gov.br/sobre/publicacoes/publicacoes/2011/pacto-nacional>. Acesso em: 24 mai. 2015.

Política Nacional de Enfrentamento à Violência contra as Mulheres. Brasília: 2011.

Disponível em:

<http://www.mprj.mp.br/documents/112957/1458116/2_Politica_Nacional_de_Enfrentament o_a_Violencia_contra_as.pdf $>$. Acesso em: 24 mai. 2015.

CORRÊA, Rúbian Coutinho (Org.). O enfrentamento à violência doméstica e familiar contra a mulher: uma construção coletiva. CNPG, 2011.

IZUMINO, Wânia Pasinato.; SANTOS, Cecília MacDowell. Violência contra as Mulheres e Violência de Gênero: Notas sobre Estudos Feministas no Brasil. E.I.A.L. Estudios Interdisciplinarios de América Latina y El Caribe, Tel Aviv, 2005. Disponível em: < http://www.nevusp.org/downloads/down083.pdf>. Acesso em: 31 jul. 2015.

JORGE, Maria Salete Bessa.; OLIVEIRA, Eliany Nazaré. Violência contra a mulher: sofrimento psíquico e adoecimento mental. RENE, Fortaleza, v.8, n. 2, p. 93-100, mai-ago, 2007.

KISS, Lígia Bittencourt.; SCHRAIBER, Lilia Bilma. Temas médico-sociais e a intervenção em saúde: a violência contra mulheres no discurso dos profissionais. Ciênc. saúde coletiva. Rio de Janeiro: vol.16 no.3, 2011. Disponível em: < http://www.scielo.br/scielo.php?pid=S1413-81232011000300028\&script=sci_arttext $>$. Acesso em: 2 jun. 2015

MARABEZZI, Natália Montezori. Direitos Humanos e Violência contra a Mulher: um estudo de gênero sobre o homicídio passional no Código Penal Brasileiro. 2010. 202 p. Dissertação (Programa de Pós-Graduação em Direito - Mestrado) - Universidade Metodista de Piracicaba, 2010.

LAURETIS, Teresa de. 1994. A Tecnologia do Gênero. In: HOLLANDA, Heloisa Buarque de (org.). Tendências e impasses: O feminismo como crítica da cultura. Ed. Rocco: Rio de Janeiro.

MENEGHEL, Stela Nazareth. Rotas críticas II: ferramentas para trabalhar com a violência de gênero. Santa Cruz do Sul: EDUNISC, 2009.

MEYER, Dagmar Estermann. Teorias e políticas de gênero: fragmentos históricos e desafios atuais. Rev Bras Enferm, Brasília (DF), 57(1):13-8, jan-fev, 2004. Disponível em: < http://www.scielo.br/pdf/reben/v57n1/a03v57n1.pdf >. Acesso em: 02 ago. 2015.

MINAYO, Maria Cecília de Souza. A difícil e lentra entrada da violência na agenda do setor saúde. Cad. Saúde Pública, Rio de Janeiro, 20(3):646-647, mai-jun, 2004. Disponível em: < http://www.scielo.br/pdf/csp/v20n3/01.pdf>. Acesso em: 01 ago. 2015.

SAGOT, Montserrat. La ruta crítica de las mujeres afectadas por la violência intrafamiliar em América Latina: estúdios de caso em diez países. Washington:

PAHO Programa Mujer, Salud Y Desarrollo, 2000. Disponível em: <http://apps.who.int/iris/bitstream/10665/165880/1/9275323348.pdf?ua=1>. Acesso em: 02 jun. 2015. 
SCHRAIBER, Lilia Bilma. Violência contra as mulheres e políticas de saúde no Brasil: o que podem fazer os serviços de saúde? Revista USP, São Paulo, v. 51, p. 104-113, 2001.

SCHRAIBER, L. B., D'OLIVEIRA, A. F. L. P. Violência contra a mulher: interface com a saúde. Interface, Comunicação, Saúde, Educação, v.3 , n.5, 1999.

SCHRAIBER, Lilian et al. A violência contra a mulher: estudo em uma unidade de atenção primária à saúde. Revista de Saúde Pública, São Paulo, v. 36, p. 470-477, 2002.

SCOTT, Joan W. Preface a gender and politics of history. Cadernos Pagu, Campinas/São Paulo, no. 3, p. 11-27,1994.

WAISELFISZ, Julio Jacobo. Mapa da Violência 2012. Atualização: homicídio de mulheres no Brasil. Centro Brasileiro de Estudos Latino-Americanos. 2012. Disponível em:

$<$ http://www.mapadaviolencia.org.br/pdf2012/MapaViolencia2012_atual_mulheres.pdf>. Acesso em: 24 mai. 2015.

\section{Sobre as autoras:}

Yanaê Maiara Meinhardt é acadêmica do Curso de Psicologia da Universidade de Santa Cruz do Sul.

Gabriela Felten da Maia é Psicóloga do Centro de Referência Especializado de Assistência Social (CREAS) de Cachoeira do Sul, Mestre em Ciências Sociais, Professora do Departamento de Ciências Humanas da Universidade de Santa Cruz do Sul. 